\title{
Proteus syndrome-a rare disease
}

\begin{abstract}
The Proteus syndrome is an extremely rare disease: about 200 cases have been described worldwide, with about 120 alive. Is characterized by pigmented verrucous nevus and skin thickening, lipomas, hemangiomas, hemihypertrophy, gigantism of the extremities, free hands, visceral abnormalities and accelerated patient rhythm in the firstyears of life. Most patients have normal neuropsychomotor development, with life expectancy between 9months and 29years, according to the severity and location of the abnormalities. Partial gigantism of the hands and/or feet is the most important manifestation of Proteus syndrome, which may be of the fingers, and are not always located on the same side of hemihipertrophy. Treatment includes emptying and liposuction, but the results are unsatisfactory by tumor recurrence and local hypertrophic scar formation.
\end{abstract}

Keywords: proteus syndrome/diagnosis, proteus syndrome/pathology, child
Volume 4 Issue 5 - 2017

\author{
Márcio Luís Duarte,' Lucas Ribeiro dos \\ Santos, ${ }^{2}$ Élcio Roberto Duarte, ${ }^{3}$ Fábio Peluzo \\ de Abreu, ${ }^{4}$ Jael Brasil de Alcantara Ferreira ${ }^{3}$ \\ 'Department of Radiology, University of São Paulo, Brazil \\ 2Department of Endocrinology, University of São Paulo, Brazil \\ ${ }^{3}$ Department of Radiology, Brasil imagem medicina diagnóstica, \\ Brazil \\ ${ }^{4}$ Department of Orthopedics, University of São Paulo, Brazil
}

Correspondence: Márcio Luís Duarte, WEBIMAGEM, Avenida Marquês de São Vicente 446, São Paulo, São Paulo, Brazil,Tel 55xx 1398| | | 2799, Email marcioluisduarte@gmail.com

Received: November 17, 2017 | Published: November 28, 2017

\section{Abbreviations: $\mathrm{CT}$, computed tomography}

\section{Introduction}

Congenital syndrome described by Cohen et al., ${ }^{1}$ in 1979 , being called Proteus (also known as Wiedmann Syndrome) in 1983 by Wiedmann ${ }^{2}$ because of the multiple variations with which it may present itself (Proteus in Greek means polymorph), being an extremely rare disease: about 200 cases have been described worldwide, with about 120 being alive. ${ }^{3}$ Characterized by pigmented verrucous nevus and thickening of the skin, lipomas, hemangiomas, hemihypertrophy, gigantism of the extremities (hands and feet), visceral abnormalities and accelerated growth rate of the patient in the firstyears of life. ${ }^{2}$

Other abnormalities were included as part of this syndrome and the most frequent are: hemihypertrophy partial or complete, macrodactyly, macrocephaly, asymmetries and exostosis, palmar or plantar giriform mass representing nevus or lipoma conjunctive, linear epidermal nevi, subcutaneous tumors composed by vascular tissue of blood, lymphatic or mixed, pronounced longitudinal growth in the firstyears of life and skeletal deformities such as scoliosis, bone hypertrophy and hyperostosis. ${ }^{4}$

Some of these alterations are also part of other syndromes, such as Klippel-Trenaunay Syndrome, Maffucci Syndrome, neurofibromatosis and others, but mesodermal and asymmetric abnormalities distinguish Proteus Syndrome from the others. ${ }^{5}$ At birth, the lesions are already present and it is possible to recognize the polymorphic nature of the syndrome. ${ }^{5}$ The changes are severe, and the patient may be very deformed, causing the patient to present stigmas that accompany him, compromising his sociability from childhood. ${ }^{5}$ Surgical treatment involves resection of soft tissue tumors, partial amputation of the hypertrophied extremities. ${ }^{5}$ All efforts should be made to minimize patient discomfort, improve the quality of life and allow social coexistence. $^{5}$

\section{Case presentation}

3year-old male patient, already with genetic diagnosis of Proteus Syndrome due to change in growth of the right foot at birth, referring that this deformity is worsening and is infected. There are no reports of complications during prenatal care, including ultrasonographic exams. There is no report of consanguinity between the parents and the grandparents, both maternal and paternal.

At birth, the patient had a right foot with gigantism, right middle hallucis, and the fifth right lateral toe (Figure 1). The remainder of the physical examination was unchanged. Radiographic examinations were performed, and the absence of the middle phalanx was noted in the fifth toe of the right foot. Throughout theyears, the evolution of the picture is clear, since, in addition to the right foot, the right leg, followed by the right knee and right thigh are being affected. Finally, the growth of the right buttock is being noticed. However, corroborating the existing literature on the disease, its neuropsychomotor development is normal.

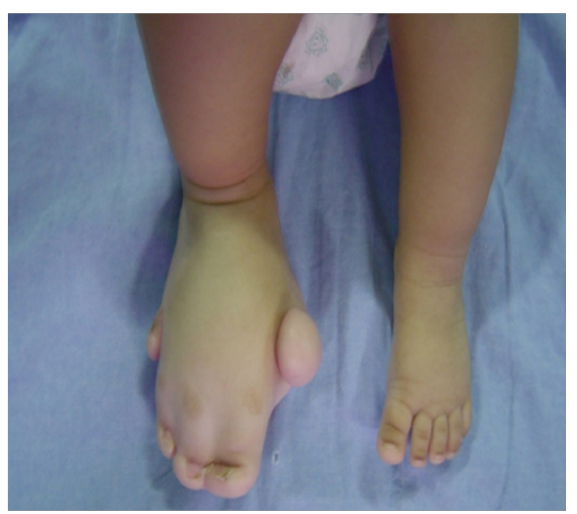

Figure I Right foot with gigantism, right middle hallucis, right fifth and lateralized right side. Normal left foot.

The patient was operated on 2 occasions. The first surgery with 3 months of life in which the right forefoot was amputated. The second surgery was performed at 2years of age for removal of local lipomas. In the present service, abdominal ultrasonography was performed detecting hepatomegaly. CT Scan of the lower limbs detected the presence of mass with attenuation equal to the fatty tissues, characterizing lipoma, extending from the posterior aspect of 
the thigh to the pelvis (Figures $2 \&$ Figure 3). After the exams, the third surgery was performed, for amputation in the right foot due to local osteomyelitis.



Figure 2 CT Scan comparing the patient's legs, demonstrating a clear volumetric increase of the right limb due to the fatty tissue.

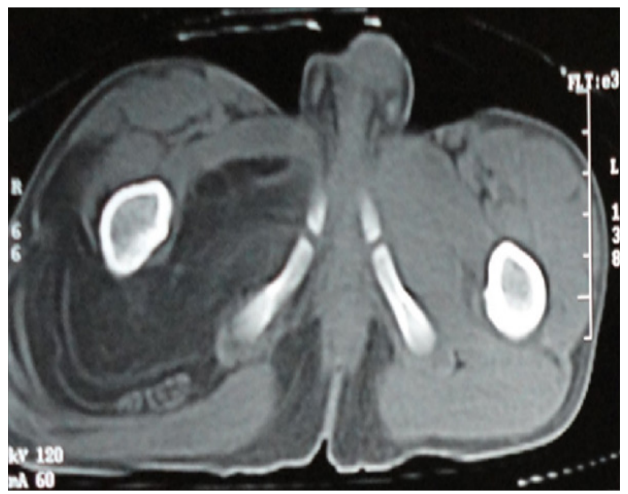

Figure 3 CT Scan comparing the patient's hips, demonstrating a clear volumetric increase of the right hip due to the fatty tissue.

\section{Discussion}

The Proteus syndrome presents genetic etiology such as mosaicism. ${ }^{6}$ The cases described are sporadic, there being no association between sex, racial group, naturalness, age of the parents at the time of conception, and the chromosome tests of both normal by current methods. ${ }^{6}$ With these data, it is suggested as an autosomal mutation that would affect the production and/or regulation of local growth factors, culminating in the overgrowth of some structures. ${ }^{7}$ Subsequently, the etiology of this syndrome was proposed as being a genetic defect, secondary to a lethal autosomal dominant mutation and that only mosaicism would allow survival. ${ }^{8}$ In the literature, we can describe a mosaic with an abnormality in the long arm of chromosome $1 .{ }^{9}$

The majority of patients have normal neuropsychomotor development, with life expectancy between 9months and 29years, according to the severity and location of the abnormalities. ${ }^{6}$ Concerning the major manifestations, it is known that hemihypertrophy is usually discrete or absent at birth (in most cases), progressing rapidly in the firstyears of life, having reduced speed with the end of school age and stopping at puberty. ${ }^{6}$ It can be partial, complete or crossed, causing the disabled member to become disabled and making it difficult to ambulate. ${ }^{6}$ Treatment involves epiphysiodesis, shortening of limbs, reduction of asymmetries, bone stretching, arthrodesis, arterial ligatures, and amputations, which are often progressive; however, the recurrence of deformities is frequent. ${ }^{1}$ Partial gigantism of the hands and/or feet is the most important manifestation of Proteus syndrome, which may be of the fingers, and are not always located on the same side of the hemihypertrophy. ${ }^{6}$ Other frequent manifestations are syndactyly, polydactyly, and clinodactyly, but there are not enough reports to define the treatment.

Subcutaneous tumors may be lipomas, hemangiomas, lymphangiomas, or any of these combinations, exhibiting very variable development and may even undergo complete regression. ${ }^{2,6}$ They occur in any part of the body and can grow to such an extent that they infiltrate local tissues, making it difficult to resect. ${ }^{6}$ Rarely associated with malignant or benign tumors. ${ }^{3}$ Treatment includes emptying and liposuction, but the results are unsatisfactory by tumor recurrence and hypertrophic scar formation at the site. ${ }^{6,10}$ These patients require a detailed clinical and complementary evaluation due to the quantity and variety of possible and diagnosable alterations with the armed propaedeutics in view of the constant progression of the disease.

\section{Acknowledgements}

None.

\section{Conflict of interest}

Author declares that there is no conflict of interest.

\section{Patient consent}

The written informed consent of the patient was obtained, for the publication of her case.

\section{References}

1. Cohen MM, Hayden PW. A newly recognized hamartomatous syndrome. Birth Defects Orig Artic Ser. 1979;15(5B):291-296.

2. Wiedemann HR, Burgio GR, Aldenhoff P, et al. The Proteus syndrome Partial gigantism of the hands and/or feet, nevi, hemihypertrophy, subcutaneous tumors, macrocephaly or other skull anomalies and possible accelerated growth and visceral affections. Eur J Pediatr. 1983;140(5):5-12.

3. Jamis-Dow CA, Turner J, Biesecker LG, et al. Radiologic manifestations of Proteus syndrome. Radiographics. 2004;24(4):1051-1068.

4. Biesecker LG, Peters KF, Darling TN, et al. Clinical differentiation between Proteus syndrome and hemihyperplasia: description of a distinctform of hemihyperplasia. Am J Med Genet. 1998;79(4):311-318.

5. Cruz R, Nunes ALS, Fortuna CMM, et al. Síndrome de Proteus: relato de dois casos e revisão de literatura. Rev bras ortop. 2015;34(4):299-303.

6. Stricker S. Musculoskeletal manifestation of Proteus syndrome: report of two cases with literature review. J Pediatr Orthop. 1992;12(5):667-674.

7. Sanchez-Lopez M, Martinez-Fernandez R, Santamaria-Carro A. Ocular manifestations in Proteus syndrome. Arch Soc Esp Oftalmol. 2007;82:175-178.

8. Happle R. Lethal genes surviving by mosaicism: a possible explanation for sporadic birth defects involving the skin. J Am Acad Dermatol. 1987;16(4):899-906.

9. Say B, Carpenter NJ. Report of a case ressembling the Proteus syndrome with a chromosome abnormality. Am J Med Genet. 1988;31(4):987-989.

10. Hornstein L, Bove KE, Towbin RB. Linear nevi hemihypertrophy, connective tissue hamartomas and unusual neoplasms in children. $J$ Pediatr. 1987;110(3):404-408 